Northwestern University School of Law Northwestern University School of Law Scholarly Commons

Faculty Working Papers

2010

\title{
FCC Regulation and Increased Ownership Concentration in the Radio Industry
}

Peter DiCola

Northwestern University School of Law, p-dicola@law.northwestern.edu

\section{Repository Citation}

DiCola, Peter, "FCC Regulation and Increased Ownership Concentration in the Radio Industry" (2010). Faculty Working Papers. Paper 33.

http://scholarlycommons.law.northwestern.edu/facultyworkingpapers/33 


\title{
Sequential Musical Creation and Sample Licensing
}

\author{
Peter DiCola*
}

February 15, 2010

\begin{abstract}
All musical creation builds on previous works. But using fragments of existing musical works in a new work can often constitute copyright infringement. Copyright law, in cases like Bridgeport Music v. Dimension Films (6th Cir. 2005), has recently increased its restrictions on musicians who wish to engage in sampling, defined as the practice of using other creators' sound recordings to create new music. The paper describes a model of copyright holders' and samplers' incentives to create in light of the need to negotiate licenses for sample-based works to avoid violating copyright law. Even in the absence of traditional transaction costs or royalty stacking, a distinct kind of inefficiency emerges. Green and Scotchmer (1995) have shown that, in the patent context, bargaining may not divide the profit from the sample-based derivative work between upstream and downstream
\end{abstract}

*Assistant Professor, Northwestern University School of Law. J.D. 2005, Ph.D. (economics) 2009, University of Michigan. I grateful to Jim Adams, Omri Ben-Shahar, Mark Clague, John DiNardo, Rebecca Eisenberg, Jessica Litman, Justin McCrary, Kembrew McLeod, the participants of the University of Michigan Intellectual Property Law and Economics Seminar, and the participants of the Chicago Intellectual Property Colloquium (jointly sponsored by Chicago-Kent and Loyola University) for their comments. All errors are my own. 
creators in a way that provides both groups with sufficient incentives to create. This paper builds on and extends Green and Scotchmer's theory by showing that innovation occurring in sequence presents a reciprocal problem. Both upstream and downstream creators have incentive constraints; pure theory cannot say which incentive constraint is less likely to be satisfied. This problem is exacerbated in the samplelicensing context because ex ante agreements are not usually possible. An optimal system for regulating sequential creation would account for the incentives of both upstream and downstream creators, to the benefit of both groups and the public. Congress and the courts have probably failed to achieve this balance, since the economic analysis of courts (especially the Sixth Circuit) has focused mainly on upstream creators' incentives.

\section{Introduction: Musical Appropriation, Borrowing, and Reference}

Sampling is the musical practice of using fragments of existing sound recordings by other musicians (called "samples") as part of a new piece of music. ${ }^{1}$ Digital technology has made sampling much less costly and has contributed to sampling's proliferation as a musical practice, playing a significant role in genres like hip-hop, electronic, and art music. Sample-based music has enjoyed enormous commercial and critical success. But copyright law presents obstacles to sampling and other forms of sequential creation. Copyright law recognizes two types of copyrights in music, protecting both (1) musical compositions and (2) sound recordings, which are often recordings of particular renditions of copyrighted compositions. Both kinds of copyrights can be implicated by a single sample, meaning that sampling often requires two separate licenses. Obtaining such licenses can be costly-or even im-

\footnotetext{
${ }^{1}$ See Mark Katz, Capturing Sound: How Technology Has Changed MuSIC138-41 (2004).
} 
possible, when copyright holders refuse to deal. In this chapter, I develop an economic model of sequential musical creation to investigate the optimal design of copyright law for handling the creation of sample-based works.

Many musical practices involve borrowing, appropriating, or taking from preexisting musical works; sampling is not unique in this regard. The long-common practice of quotation involves taking a short phrase from a prior composition and working it into a new composition. Quotation differs from sampling because it does not copy part of an existing sound recording to make its reference, but it too involves borrowing from prior material. "Covers" are re-recordings of musical compositions that other musicians have recorded previously. Cover artists can tailor the composition to their own styles and make their own arrangements, but only up to a point. Less literal forms of borrowing occur all the time when musicians allude to previous music, adopt another musician's style, or work in a genre developed by countless previous musicians. Most importantly, almost all music uses basic building blocks like notes, scales, chords, compositional forms, and instruments. Only the rarest of musical works fails to use techniques of appropriation, borrowing, or reference. ${ }^{2}$ Thus, all musical innovation involves combination and recombination of many elements, along with the addition of new elements, to produce a unique creation. But copyright law contains stark differences in how it treats the various modes of musical borrowing. As Section 2 describes, the recent Bridgeport case has staked out a new extreme in the disfavored treatment of sampling under U.S. copyright law.

Economically, musicians' production functions use existing musical works as inputs of production. ${ }^{3}$ Section 3 explores the implications of assuming that samplers negotiate with licensors for the use of ex-

\footnotetext{
${ }^{2}$ See, e.g., Joanna Demers, Steal This Music: How Intellectual Property Law Affects Musical Creativity 31-70 (2006).

${ }^{3}$ For a model focused on complete duplication that also recognizes that creative works are inputs to subsequent creative works, see William M. Landes \& Richard A. Posner, The Economic Structure of Intellectual Property Law 71-84 (2003).
} 
isting works, based on the sample-licensing negotiations that occur in the music industry. The parties' inability to write contracts before production that allow both licensors and licensees to cover their costs results in what the patent literature calls the division-of-profit inefficiency. Circumstances exist in which either samplers' or samplees' incentive constraints result in their music not being created. This illustrates how copyright's regime for sampling can backfire when it attempts to maximize copyright holders' incentives rather than providing a balance between copyright holders and subsequent users. ${ }^{4}$ When the sample-based work is not created, the copyright holder in the existing work receives no licensing revenue, harming the creators of existing works that the stronger copyright regime was supposed to help. The final subsection of Section 3 extends the model to the multiple-licensor setting, to capture the situation in which samplebased songs are collages of many complementary samples.

Copyright law's regime governing musicians' use of existing music plays a large role in what existing music can enter the production process, when licenses become necessary, and how much licenses (and the licensing process) cost. The particular institutions and relationships involved in licensing negotiations will also play a significant role. By specifying a formal model of how law, institutions, and incentives interact in the context of sample licensing, this paper aims to provide systematic understanding of the economic forces at work. Ideally, such modeling could someday result in a model with both testable predictions and measurable variables - a tall order in the copyright context. In the meantime, studying the incentives involved in sample licensing might allow for a better design for copyright's handling of sequential musical creation.

\footnotetext{
${ }^{4}$ Cf. Jessica Litman, Digital Copyright 77-86 (2001) (describing the shift in copyright's overarching rationale from a bargain between creators and the public to an attempt to maximize creators' incentives).
} 


\section{Copyright's Regime for Sequential Musical Creation}

This section provides some background in music copyright. It also explains the statutory provisions and judicial opinions that govern musical appropriation, borrowing, and reference in general, and sampling in particular.

\subsection{Copyright Basics}

As mentioned above, two kinds of copyrights potentially apply to any song or other piece of music: a sound recording copyright ${ }^{5}$ and a musical composition copyright. ${ }^{6}$ In popular songs, and most classical and jazz pieces, the sound recording is a particular recorded rendition of an underlying musical composition, which includes the melody, chords, rhythm, structure, and lyrics. The two copyright holders in a song may be identical but often they are distinct. For example, Bob Dylan often records his own compositions, but the Byrds also recorded versions of many of his compositions.

Recording artists often transfer their sound recording copyrights to record labels in return for financing and marketing their works, as well as advance and royalty payments. Composers and songwriters generally sign contracts with publishers to administer their copyrights, splitting the revenue. In addition, many composers belong to one of the performing rights organizations, ASCAP, BMI, or SESAC. These organizations administer blanket licenses for radio stations, concert venues, and others to perform their members' songs publicly. ${ }^{7}$ In

\footnotetext{
${ }^{5}$ Sound recordings are defined as "a series of musical, spoken, or other sounds [except for movie soundtracks] ... regardless of the nature of the material objects ... in which they are embodied." 17 U.S.C. $\S 101$ (2000). They were not protected under federal law until 1971. Sound Recordings Act, Pub. L. No. 140, 85 Stat. 39 (1971).

${ }^{6}$ The copyright code uses the term "musical work," but does not define it except to say that lyrics are included. 17 U.S.C. $\S 102(a)(2)(2000)$.

${ }^{7}$ For a primer on the music industry, see generally Donald S. PAssman, All You
} 
the models below, I will treat the sound recording copyright holders and the musical composition copyright holders in existing works as single entities. In reality such agents are more complex, but I assume that their profit-maximizing incentives are aligned sufficiently for the analysis to be meaningful.

Musical compositions come with five exclusive rights: reproduction, distribution, preparation of derivative works (such as adaptations and translations), performance, and display. Sound recordings come with the same first three rights, a performance right limited to certain online performances (i.e., leaving out performances on traditional AM and FM radio), and no display right. ${ }^{8}$

Using a sample often involves infringing exclusive rights in both a copyrighted composition and a copyrighted sound recording. This is because taking a fragment of a sound recording necessarily means using the part of the composition underlying that fragment. For instance, using a sample of Marvin Gaye and Tammi Terrell singing "Ain't no mountain high enough / Ain't no valley low enough" means not only using a recording of Gaye's and Terrell's voices singing those lines, but also using the melody, harmony, and rhythm that make up the lines in the composition. A single action can infringe multiple rights at once; sampling often does so. Using a sample can constitute a reproduction. It can also constitute a derivative work, because taking a fragment of an existing work and placing it into a sound collage is a form of adaptation. Additionally, sampling can also implicate the copyright holders' distribution and performance rights if the samplebased song is marketed to the public, played live, or played on radio or television).

The foregoing discussion uses conditional language ("can infringe"; "might infringe") to address whether a sample actually infringes a composition, sound recording, or both. The conditional verb tense is necessary for three sets of reasons. First, not all compositions and

Need to Know About the Music Business (2000).

817 U.S.C. $\S 106$ (2000). 
recordings are subject to copyright protection. For example, some sound recordings pre-date federal or state copyright protection. Other copyrights may have existed at one time, but later expired because of copyright's limited duration or because the copyright was not renewed at a time the law still required renewal. ${ }^{9}$ Moreover, copyright owners can voluntarily put works into the public domain, meaning that the public can use them freely.

Second, a sample might not infringe because even currently valid copyrights are subject to limitations and exceptions. For instance, courts have recognized a "de minimis" threshold, meaning that using very small portion of a copyrighted work will not necessarily constitute infringement. ${ }^{10}$ Another important limitation on copyright protection is the fair use doctrine, which gives infringement defendants an affirmative defense for activities "such as criticism, comment, news reporting, teaching, ... scholarship, or research." 11 Many other limitations to copyright, both broad and narrow, exist in the copyright code and in case law, but these are the most important provisions for the model in this chapter.

The third and final reason a sample may not infringe a copyright would be a failure on a copyright-infringement plaintiff's part to demonstrate that the sample-based song is "substantially similar" to the plaintiff's recording or composition. Some infringement cases involve identical copies of an entire work. But many other infringement cases involve things that come close but are not identical - the idea being that altering a minuscule detail of a copyrighted work should not exonerate a brazen copier. Courts do not require a complete, perfect copy for infringement. Instead, courts adjudicate claims for

\footnotetext{
${ }^{9}$ Copyright is also limited in time, expiring 70 years after an author's death. 17 U.S.C. $\S 302(\mathrm{a})$ (2000). Copyrights lasts for 95 years after publication (or 120 years after creation, whichever comes first) for a "work for hire," meaning a work either commissioned or performed by an employee within the scope of employment. Id. $\S \S 101,302$.

${ }^{10}$ See Judge Newman's discussion in Ringgold v. Black Entertainment Television, 126

F.3d 70. 74-76 (1997) (declining to find the defendant's use de minimis).

${ }^{11} 17$ U.S.C. $\S 107(2000)$.
} 
infringement of the reproduction and derivative-works rights based on the substantial similarity test. ${ }^{12}$ Because sampling is a unique form of musical borrowing, one treatise writer has developed a modified concept of substantial similarity called "fragmented literal similarity" to handle sampling cases in which "the similarity [between two parties' works], although literal, is not comprehensive - that is, the fundamental substance, or skeleton or overall scheme ... has not been copied; no more than a line, or a paragraph, or a page or chapter of the copyrighted work has been appropriated." 13 The treatise provides "no easy rule of thumb" but advises courts to consider the sample both quantitatively and qualitatively with respect to the "plaintiff' $s$ " work. ${ }^{14}$ The cases in the next subsection will illustrate how that doctrine applies in the sampling context.

The dual nature of music copyright - splitting the rights in music into composition copyrights and sound recording copyrights - means that the number of necessary licenses is generally at least double the number of sampled songs. The limited nature of copyright means that samplers will often, but not always, require a license to use existing works. In particular, samplers are free to use works that were never copyrighted and works whose copyrights have expired. Samplers may also engage in non-infringing uses of copyrighted works without permission or a license, but such uses may be difficult, uncertain, and costly to identify. In the models of this chapter, non-infringing uses or works not under copyright have a licensing fee of zero, but they may come with information costs to verify their status as non-infringing.

\subsection{Sampling Case Law}

Digital technology and the rise of hip-hop led to an increase in sampling activity among musicians in the 1970s and 1980s. By the 1980s,

\footnotetext{
${ }^{12}$ See Julie E. Cohen et al., Copyright in a Global Information Economy 353-94 (2002).

${ }^{13}$ Nimmer on Copyright §13.03[A][2] (2005).

${ }^{14} I d$. (emphasis in original).
} 
copyright owners began to file lawsuits, many of which settled out of court. In 1991, Grand Upright Music v. Warner Brothers Records was the first published judicial opinion to establish that sampling was copyright infringement. ${ }^{15}$ Rapper Biz Markie admitted to sampling the song "Alone Again (Naturally)" by Gilbert O'Sullivan. Judge Kevin Duffy's opinion famously opened with the phrase "Thou shalt not steal," and found that Biz Markie's sample infringed O'Sullivan's composition copyright. ${ }^{16}$ Although the opinion lacked a thorough analysis of copyright law, the case signaled to the music industry that samples should be cleared to avoid an infringement lawsuit.

More lawsuits ensued. ${ }^{17}$ Each sampling case is decided based on the specific facts and context.

Three particularly prominent sampling cases - one about fair use, two about the de minimis threshold-illustrate the difficulties of discerning the boundary between infringing and non-infringing samples.

The Supreme Court addressed a sampling-related dispute that began when rap group 2 Live Crew sampled parts of Roy Orbison's "Pretty Woman." The Court held that a parody - even a commercial parody for which permission was sought and then denied-could be a fair use of the composition it mocked. ${ }^{18}$ The Court also suggested

15780 F. Supp. 182 (S.D.N.Y. 1991).

${ }^{16} I d$. at 182 .

${ }^{17}$ See, e.g., Williams v. Broadus, 99 Civ. 10957 (MBM), 2001 U.S. Dist. LEXIS 12894 (S.D.N.Y. August 27, 2001) (holding that a genuine factual issue existed whether plaintiff Marley Marl's song, which sampled Otis Redding's "Hard to Handle," was itself an unauthorized derivative work, which would exonerate defendant Snoop Dogg for sampling Marley Marl's song); Fantasy, Inc. v. La Face Records, No. C 96-4384 SC ENE, 1997 U.S. Dist. LEXIS 9068 (N.D. Cal. June 24, 1997) (dismissing the plaintiff's complaint for creating an unauthorized derivative work because the sampled recording, made in 1971, predated federal protection for sound recordings, which did not occur until 1972); Jarvis v. A\&M Records, 827 F. Supp. 282 (D.N.J. 1993) (denying summary judgment for defendant group C\&C Music Factory because it might have infringed by sampling a qualitatively important keyboard part and short but qualitatively important lyrical phrases from a song by plaintiff composer Boyd Jarvis).

${ }^{18}$ Campbell v. Acuff-Rose Music, Inc., 510 U.S. 569, 581-85 (1994). 
that other, non-parodic, "transformative uses" could qualify as fair use. ${ }^{19}$ But subsequent case law has not established anything like the (relatively) safe harbor that parody enjoys.

A unique and interesting case arose after the Beastie Boys sampled a three-note melodic phrase - C, D-flat, C, played on the flute over an overblown background C-from Newton's composition "Choir." 20 The Beastie Boys had licensed the sound recording from Newton's record label. But they had not licensed the underlying composition from Newton himself, who owned the publishing rights. The Ninth Circuit affirmed the district court's holding that the Beastie Boys' use was de minimis, applying an ordinary observer interpretation of that exception to infringement. ${ }^{21}$ The court held that the three notes were " 'a common building block tool.' that 'has been used over and over again by major composers in the 20th century.' "22

Two years later, Bridgeport Music, Inc. v. Dimension Films held that no de minimis threshold applied to sound recordings. ${ }^{23}$ "100 Miles and Runnin'," a song by N.W.A., sampled two seconds from a guitar solo of the George Clinton song "Get Off Your Ass and Jam." The two-second sample was a recording of three notes from a single chord played in rapid succession (what musicians call an arpeggio). "100 Miles and Runnin'" was used in the movie I Got the Hook$U p$ without a synchronization license for the sound recording. ${ }^{24}$ The court read Section 114(b) of the copyright code, which explicitly excludes "entirely . . . independently created" works from the reach of the reproduction and derivative-works rights of sound recording copyrights, ${ }^{25}$ to imply the converse: that any work not entirely in-

\footnotetext{
${ }^{19} I d$. at 579 .

${ }^{20}$ Newton v. Diamond, 388 F.3d 1189, 1191 (9th Cir. 2003).

${ }^{21} \mathrm{Id}$. at 1193 ("To say that a use is de minimis because no audience would recognize the appropriation is thus to say that the use is not sufficiently significant.").

${ }^{22}$ Id. at 1196 (quoting testimony defendants' expert Dr. Lawrence Ferrara).

${ }^{23} 410$ F.3d 792 (6th Cir. 2005). In other words, the court held that, for sound recordings, the de minimis threshold is zero.

${ }^{24}$ The musical composition had received a synchronization license. Id. at 796 .

${ }^{25} 17$ U.S.C. $§ 114$ (b) (2000).
} 
dependently created infringes. ${ }^{26}$ The end result is that in the Sixth Circuit (Tennessee, Kentucky, Ohio, and Michigan) there is no de minimis threshold for the infringement of copyrighted sound recordings. Or, as put it: "Get a license or do not sample." ${ }^{27}$ The court allowed for the possibility of fair use but did not rule on that issue. ${ }^{28}$ While other circuits may reject this approach in the future, Bridgeport has effectively become the law of the land for the time being. Since most recordings are marketed nationwide, infringement plaintiffs will generally have the opportunity to file in the Sixth Circuit.

The copyright policy of Bridgeport, along with other cases holding that sampling can be copyright infringement, motivates this chapter's analysis. Should copyright holders enjoy a strong property right in samples - small fragments of larger works? Or would it be more efficient for copyright law treat some samples as too small to infringe?

\section{A Model of Sequential Musical Cre- ation}

This section explores the assumption that samplers negotiate with licensors for the use of existing works, rather than taking input prices as given from a market for samples. The prevailing music-industry practice is to negotiate sample licenses on a case-by-case basis. Although some copyright owners offer a menu of licensing fees, with licenses available to all comers at a certain price, most copyright owners engage in individual negotiations with would-be samplers.

\subsection{Setting up the model}

Suppose that a new piece of music requires using a digital sample of one existing piece of copyrighted music. Assume that the new

\footnotetext{
${ }^{26}$ Bridgeport, 410 F.3d at 800.

${ }^{27} I d$. at 801 .

${ }^{28} I d$. at 805 .
} 
derivative work will have no value without incorporating the sample. ${ }^{29}$ In addition, assume that the new piece of music definitely infringes both the composition and sound recording copyrights in the sampled piece of music. If the sampler failed to obtain licenses from both copyright holders, then he or she would be found liable and his or her payoff would be significantly negative. Thus, without licenses the new work will not be produced.

The original, sampled work would yield value to consumers of $v$, which reflects the combined value of its recording and underlying composition (experienced as a unified whole by listeners). The composer and recording artist of the existing work must both make their contributions for the existing work to have value; if either declines to produce her contribution, the existing work has zero value and is not created. The new, sample-based work has a value to consumers of $q$. The creator of the sample-based song is both composer and recording artist for that song.

Musicians have fixed costs of production, which include the costs of capital (e.g. recording equipment) and labor (e.g. session musicians), and zero variable costs. The fixed costs of production to specific to each of the three works are: $c_{D W}$ for the new, sample-based work; $c_{S R}$ for the preexisting sound recording; and $c_{M C}$ for the preexisting musical composition.

The optimal marginal cost of information once it has been created is (very close to) zero, but copyright law allows copyright owners to maintain a price for their goods that is meaningfully greater than zero. The parameters describing the consequences of this feature of copyright law are as follows: Copyright holders can collect revenue equal to a fraction $\pi$ of their works' value to consumers. Society experiences deadweight loss $l$ every period a work is under copyright. Both $\pi$ and $l$ are functions of the duration of copyright and the social discount rate, but making that explicit does not affect the model's

\footnotetext{
${ }^{29}$ The assumption that the derivative work loses all its value without the sample will be relaxed later in the chapter.
} 
basic implications.

Thus, the total social value will be positive for each work under the following conditions [the "positive social value conditions"]:

- For the new, sample-based song: $q(1-l)-c_{D W}>0$

- For the existing, sampled song: $(v+q)(1-l)-c_{M C}-c_{S R}-$ $c_{D W}>0$

The goal of the model is to demonstrate that even when these positive social value conditions hold, one or both songs might not be created. This is true even with perfect information, risk-neutrality of all agents, and zero transaction costs (all of which the model assumes).

\subsection{Division of profit: The source of ineffi- ciency}

What will drive the model's results are two key facts together with insights about bargaining, credible threats, and backward induction. First, sampling may occur long after the sampled work is created. The sampler's identity is not known when the original, sampled work is created, making an ex ante agreement impossible. If the sampler stands to make profits but the sampled musicians would fall short (looking ahead to sales of their work and the Nash-bargaining outcome of licensing negotiations), there is no way the sampler can promise to give the sampled musicians a better deal - the sampler doesn't know he wants to be a sampler yet, because the original work doesn't exist yet.

Second, if the original work exists and the sampler chooses to sample it, the sampler does not know a license is necessary until after sinking her costs of producing her sample-based song. This stems from the institutional details of musical production. A musician often does not know what sample is desired until she spends the studio time to create a song with that sample. This makes licensing before creation of the sample-based work very rare. Given that, if the sampler stands to fall short of making a profit (looking ahead to sales of her work and the 
Nash-bargaining outcome of licensing negotiations), there is no way for the sampler to make a credible threat not to create the sample-based song - if licensing negotiations have started, the sampler's production costs are already sunk.

The model presented here is an adaptation of a model by Green and Scotchmer that focused on the patent context, particularly the issue of patents for basic research. ${ }^{30}$ In the context of sequential innovation, where basic research may lead to commercially valuable products, a danger exists that - without patent protection-basic researchers will not have sufficient incentives for their research. This can occur even when that basic research and all the commercially marketable products it would lead to would have net positive social value.

The contribution of this chapter is to demonstrate that the problem is reciprocal. Not only can the absence of intellectual property protection endanger the creation of upstream works, the presence of intellectual property protection can endanger the creation of downstream works. When society would benefit from both works, the incentives of both copyright owners of sampled works and the musicians who sample matter.

The game play proceeds as follows:

1. The values of all variables are known and taken as given.

- Consumer demand determines the value of each work, $v$ and $q$.

- Music production technology and the idiosyncrasies of each work determine the cost, $c_{X X}$, to each musician.

- The parameters $\pi$ and $l$ are commonly known.

- Only the identity of the sampler is not known to the creators of the sampled work.

2. The composer of the original work decides whether to create the

\footnotetext{
${ }^{30}$ See Jerry Green \& Suzanne Scotchmer, On the Division of Profit in Sequential Innovation, 26 RAND J. ECON. 20 (1995), particularly the presentation in SuzANnE Scotchmer, InNovation And InCEntives135-42 (2004).
} 
composition.

3. The recording artist of the original work decides whether to make the recording.

4. If either the composition or the recording is not created, the original work will not exist and the game ends. If the original work does exist, the sampling musician decides whether to create the sample-based work.

5. If the sample-based work exists, then the sampler must obtain two licenses, one from the composer and one from the recording artist, or else the sample-based work cannot be released commercially and garner revenue.

Solving the model requires backward induction and thus starts with the fifth and last step: licensing negotiations. Bargaining among the sampler and the samplees takes place according to the three-person licensing game described in Appendix A. As a result of bargaining, the parties split $q \pi$ roughly $\frac{1}{3}, \frac{1}{3}, \frac{1}{3}$, the Nash solution. As Appendix A shows, the Nash result is approximated as the negotiating parties' subjective (commonly held) discount factor approaches unity.

At the fourth step, the sampling musician decides whether to produce her song or not. She will do so whenever the revenue she can collect exceeds the licensing fees she must pay and her production costs:

$$
q \pi<\left(\frac{2 q}{3}\right) \pi-c_{D W}
$$

Thus, society will lose out on sample-based works that have positive social value when:

$$
q(1-l)-c_{D W}>0 \quad \text { but } \quad\left(\frac{q}{3}\right) \pi<c_{D W}
$$

In other words, when the sampler's one-third share of the profit from the derivative work is not great enough to cover the fixed costs of producing the work, then the derivative work will not be produced.

This is partly a result of the three-way split of the derivative work's profits. But at its root, it is a result of the institutional setting; 
samplers typically do not seek out licensors until their sample-based works have already been created. This makes the case of ex ante licensing, more relevant in the patent context of Scotchmer and Green, unusual in this context. Only ex post licensing is realistic in the music industry, when songs generally have to be created and heard to be evaluated. If ex ante licensing were possible, then the costs as well as the revenues of the derivative work could be shared among the original sound recording copyright holder, the original musical composition copyright holder, and the sampler.

At the third step, the recording artist of the sampled work decides whether to record the composition, if it exists. The compulsory license for cover versions compositions gives the recording artist of the sampled work leverage to pay the composer a fixed fraction $m<\frac{1}{2}$ of the sampled work's revenue. The composer does worse than the two-person Nash-bargaining result of $\frac{1}{2}, \frac{1}{2}$. As mentioned above, a recording artist can cover a composition without the composer's permission if it has been commercially released once. But this compulsory license for second, third, and nth versions has historically influenced the licensing fee for the first recording of a composition as well. If a composer refused to grant the recording artist a license to be the first to record a composition, the recording artist would merely have to wait until another artist recorded the song, at which point the recording artist could immediately take advantage of the compulsory license. Thus, in music-industry practice, composers typically receive the current statutory rate as a royalty on sales of recordings. ${ }^{31}$

Thus, at the third step, the recording artist decides whether the fraction $(1-m)$ of the revenue $v \pi$ from the sampled work is sufficient to cover her costs $c_{S R}$. At the second step, the composer decides whether the fraction $m$ of the revenue $v \pi$ from the sampled work is

\footnotetext{
${ }^{31}$ See 17 U.S.C. $\S 115(\mathrm{a})(2)$; see also Passman, supra. The current rate is 9.1 cents per copy sold or 1.75 cents per minute, whichever is greater. U.S. Copyright Office, Mechanical License Royalty Rates (May 30, 2006), at http://www.copyright.gov/carp/m200a.html (last visited May 17, 2009).
} 
sufficient to cover her costs $c_{M C}$.

Steps two and three determine whether any music is produced at all. If the composer and recording artist of a work cannot cover their costs through sales of their own song plus licensing fees from the song that samples theirs, they will not produce. The social value of the original, sampled work includes the value of the new, sampling work that depends on it. Society will lose out on two works that collectively have positive social value when:

$(v+q)(1-l)-c_{M C}-c_{S R}-c_{D W}>0 \quad$ but $\quad\left[(1-m) v+\frac{q}{3}\right] \pi<c_{S R}$

or:

$(v+q)(1-l)-c_{M C}-c_{S R}-c_{D W}>0 \quad$ but $\quad\left(m v+\frac{q}{3}\right) \pi<c_{M C}$

The logic of these equations is similar. If one of the original creators cannot cover its costs - even with the help of receiving one-third of the revenue from the derivative work - then neither the original nor the derivative work will be produced.

Two inefficiencies are possible. The creators of either the prior, sampled work or the later, sampling work could fail to meet their incentive constraints. It might seem counter-intuitive that inefficiency could arise from a perfect information, zero-transaction-cost model with no uncertainty and risk-neutral agents. The driving force of the inefficiency is that musicians sink their costs before negotiating licenses, whether for samples of or samples used in their work. Viewed from another angle, the source of the inefficiency is the timing of the agents' actions. The sequence of events means that a single piece of information is missing when production occurs: the identity of the licensor or licensee they will need to negotiate with to authorize the use of a sample.

\subsection{Comparing two copyright regimes}

The preceding subsection describes the inequality conditions that determine when socially desirable works will not be created. Those conditions resulted in part from the assumption that the sample infringed 
the original work's copyright. Making the opposite assumption, that the sample does not infringe the original work's copyright, would alter the conditions for inefficiency as follows. Inefficiency would occur whenever any one of the following pairs of inequalities holds:

$$
\begin{array}{ccc}
q(1-l)-c_{D W}>0 \quad \text { but } & q \pi<c_{D W} \\
(v+q)(1-l)-c_{M C}-c_{S R}-c_{D W}>0 & \text { but } & (1-m) v \pi<c_{S R} \\
(v+q)(1-l)-c_{M C}-c_{S R}-c_{D W}>0 & \text { but } & m v \pi<c_{M C}
\end{array}
$$

Each pair of inequalities has a positive social value conditions and an incentive constraint; there is one pair for each musician in the model, as in the previous subsection. The only difference is that the licensingfee terms, $\frac{q}{3} \pi$, have been eliminated.

Switching to a regime in which samples do not receive copyright protection tilts the likelihood toward the sampling musician being able to meet her incentive constraint. In particular, society gains samplebased derivative works - relative to the copyright regime - whenever $\frac{q \pi}{3}<c_{D W}<q \pi$ and the recording artist and composer of the original work can meet their incentive constraints without licensing fees, i.e., $(1-m) v \pi>c_{S R}$ and $m v \pi>c_{M C}$. When these conditions hold, a no-copyright regime produces two works whereas the copyright-insamples regime produces only one work, the original song. That is the marginal benefit of eliminating copyright in samples.

At the same time, moving to a no-copyright regime means it is less likely that the sampled musicians will meet their incentive constraint. Under this regime, society loses original works - relative to the copyright regime-whenever $(1-m) v \pi<c_{S R}<\left[(1-m) v \pi+\frac{q \pi}{3}\right]$ or $m v \pi<c_{M C}<\left[m v \pi+\frac{q \pi}{3}\right]$, provided that the sampling artist can still afford the cost of production while paying licensing fees i.e., $\frac{q \pi}{3}>c_{D W}$. When these conditions hold, a no-copyright regime produces no works at all, because at least one of the creators of the original work cannot meet her incentive constraint. Those lost works are the cost of shifting away from copyright protection for samples. 
Under these same conditions, the regime with copyright in samples would foster the production of both works.

Which regime is more efficient, copyright or no copyright in samples, depends on the distributions of the random variables $v, q, c_{M C}$, $c_{S R}$, and $c_{D W}$, as well as the parameters $\pi, l$, and $m$. The specifics of these distributions and parameters determine whether the value of the works gained outweighs the value of the works lost; in general, either regime could be more efficient.

Here is an example where a no-copyright regime is more efficient than a copyright-in-samples regime. Let $\mathbf{U}(a, b)$ denote the uniform distribution over the interval $[a, b]$ and assume the following:

- $v \sim \mathbf{U}(0,4)$

- $c_{M C} \sim \mathbf{U}(0,0.9)$

- $c_{S R} \sim \mathbf{U}(0,0.9)$

- $q \sim \mathbf{U}(0,4)$

- $c_{D W} \sim \mathbf{U}(0,2)$

- $\pi=0.5$

- $l=0.25$

- $m=0.5$

Under these assumptions, the no-copyright regime is superior approximately 13.6 percent of the time, with derivative works of mean value 1.11 being lost. The total gain to having no copyright in samples is thus 0.151 on average (13.6 percent times 1.11). Also under the above assumptions, the copyright-in-samples regime is superior 6.59 percent of the time, with original and derivative works of combined mean value 2.24 being lost. The total loss from having no copyright in samples is thus 0.148 on average. The gain to switching to the no-copyright regime exceeds the cost. The no-copyright regime is more efficient under the above assumptions.

The above is just one example of what might happen in the sequential innovation context between a sampling musician and the musicians 
she samples. It proves, by counterexample, that copyright protection for samples can be less efficient than having no copyright protection for samples. This is true even in the absence of transaction costs, uncertainty, risk-aversion, imperfect information, externalities, or other market imperfections. The only barriers to efficiency are the timing of production and the necessity of sinking one's production costs before one can grant or obtain a license to sample.

\subsection{Extension: Multiple samples within one derivative work}

A straightforward way to extend the model from the single-sample to the multiple-sample case is to approximate the result of $n$-way bar-

gaining with the Nash solution: each party receives $\frac{1}{n}$ of the bargaining surplus. In the model, the parties are bargaining over the returns to the sample-based work, $q \pi$. With one sample, each party received $\frac{q \pi}{3}$, because there were three parties at the bargaining table: the original composer, the original recording artist, and the sampling musician. With two samples, there would be five parties at the bargaining table (two original composers, two original recording artists, and the sampling musician). In general, each licensor and the sampling musician will receive:

$$
\frac{q \pi}{2 n+1} \quad \text { where } \quad n \quad \text { is the number of samples }
$$

Taking the limit of this expression, we see:

$$
\lim _{n \rightarrow \infty} \frac{q \pi}{2 n+1}=0
$$

As the number of samples increases, the sampling musician's revenue approaches zero. Each licensor's licensing revenue also approaches zero (meaning that each licensor's incentive constraint approaches what it would be if the sample-based work did not exist).

This simple extension of the model captures a kernel of truth about the real world of sample licensing. In practice, musicians who use 
multiple samples per song - creating, say, a collage of twenty or more existing songs - cannot hope to obtain the necessary licenses without pushing their revenue to zero or less. ${ }^{32}$

\section{Extension: Adjustment to sample length is possible}

The model of the previous section assumes that the entire value $q$ of the downstream work depends on its sample of the upstream work. In that context, one can only compare two extremes of copyright law: copyright protection for samples or no such copyright protection. In this section, I extend the model such that: (a) only a fraction of the downstream work's value depends on the sample and (b) the fraction of value that does depend on the sample is proportional to the sample's length in time. This allows investigation of a third policy option: copyright protection for samples with limitations and exceptions.

The de minimis threshold for copyright infringement embodies the idea that some uses of existing music are so small that the law should not recognize them as violations. It was the subject of the recent Bridgeport decision, which ruled that no de minimis threshold exists for sound recordings analogous to that for compositions. The de minimis threshold lends itself straightforwardly to quantitative modeling. Another important limitation on copyright, fair use, involves a larger set of considerations and would require a richer set of variables to analyze. But one consideration in fair use analysis is the quantity used of the original work, meaning that a model of the de minimis threshold takes one step in the direction of modeling fair use.

Instituting such a threshold allows the law some breathing room, which could have important benefits in terms of samplers' incentives

\footnotetext{
${ }^{32}$ The possibility of licensing fees that exceed the sales revenue of the sample-based work could be captured with a model where each sample has its own market with a marketdetermined (rather than bargaining-determined) price. In a market-based model, nothing would constrain the samples from exceeding sales revenue.
} 
and in terms of avoiding the transaction costs of licensing. The de minimis threshold will also have the consequence of providing some samplers with the incentive to shorten their samples, to take advantage of copyright law's choice to limit its own reach.

\subsection{Revising the model}

Suppose that copyright subsists in any fraction [measured in time] of a musical work $\bar{y} \in(0,1)$. Each sampler, in the one-sample set up, will have a desired sample length $y^{*}$. The new, sample-based work has an associated loss function $L(y)$ which measures the proportional loss in value from adjusting the length of a sample downward from $y^{*}$. This loss function has the form:

$$
L(y) \equiv\left(\frac{y^{*}-y}{y^{*}}\right)^{\frac{1}{\lambda}}
$$

with $y^{*} * \in(0,1)$ denoting the desired sample length and $\lambda \in(1, \Lambda)$ for some large, finite $\Lambda$ parameterizing the degree of distaste for moving away from the most desired sample. Higher $\lambda$ means more distaste for deviations from the optimum. As a consequence of this functional form, $L(y) \in(0,1) .{ }^{33}$ There is an implicit-and admittedly imperfect, since it puts the qualitative dimension of sample choice asideassumption that shorter samples contribute less to the value of the derivative work, and thus it is most desirable to decline to compensate the tiniest samples.

Given this loss function, the commercial value of the new, samplebased work is now $q \cdot[1-L(y)]$. Under what circumstances will the musician reduce the sample and avoid the licensing fees? Whenever $q \cdot[1-L(y)] \geq \frac{q}{3}$ (the musician's approximate share of the profits after licensing) - that is, whenever $L(y) \leq \frac{2}{3}$. The $y$ that makes this equation hold with equality will depend on the sampler's particular

\footnotetext{
${ }^{33}$ I assume that the licensor never wishes to grant (and the licensee never wishes to use) a larger sample than desired. Thus, there is no need for a quadratic, i.e. two-sided, loss function.
} 
parameters $y^{*}$ and $\lambda$, and implicitly depends on the equilibrium of the three-person bargaining game.

As a result of making the sampler's decision problem more flexible, we now have three cases:

1. The sampler need neither license nor adjust he sample, because $y^{*}<\bar{y}$. If the sampler's desired sample length is below the de minimis threshold of copyright law, the sampler will earn $q \pi-$ $c_{D W}$ whenever that expression is positive. The only danger of social loss is whether $\frac{q \pi}{3}$ was needed to incentivize the preexisting sound recording or musical composition.

2. The sampler can alter the sample, even though $y^{*} \geq \bar{y}$, to make the chosen $y<\bar{y}$. In this case, all we need for the sample-based work to be created is:

$$
q \cdot[1-L(y)] \pi \geq c_{D W}
$$

For this to be true, we need $y^{*}$ to be between $\bar{y}$ and $\left(\frac{1}{1-\left(\frac{2}{3}\right)^{\lambda}}\right) \bar{y}$. [To see this, set $L(\bar{y})=\frac{2}{3}$.] Again, the harm to social welfare involves any original, sampled works for which $\frac{q \pi}{3}$ was needed to incentivize the preexisting sound recording or musical composition.

3. The sampler would rather license than alter the sample because $y^{*}>\bar{y}$ and $L(\bar{y})>\frac{2}{3}$. Then the original inequalities hold from the simplest case above (the case without adjustment of samples).

\subsection{Three different copyright regimes}

Determining the optimal level of $\bar{y}$ requires an analysis of what works are gained or lost to society under different scenarios, corresponding to different levels of $\bar{y}$. In each of the three scenarios, there are up to to three cases to analyze, corresponding to different ranges of the 
sampler's value of $y^{*}$ in relation to $\bar{y}$. Throughout the discussion, I mean to refer to works with positive social value. ${ }^{34}$

No copyright over derivative works. This corresponds to $\bar{y}=1$. Under that condition, any value of $y^{*}$ puts us into case (1) above. No sample of any length necessitates obtaining a license. Socially valuable derivative works are not created whenever $q \pi<c_{D W}$. Nor are they created if either $(1-m) v \pi<c_{S R}$ or $m v \pi<c_{M C}$, since the creators of the original, sampled song cannot make a positive profit.

Complete copyright over derivative works. Next consider the consequence of $\bar{y}=0$. Here, only case (3) is relevant, because there is no de minimis threshold and thus there is no reason in this simple setup for the sampler to alter the sample length. Society gains creative works with respect to the no-copyright scenario when both original artists cross the profitability threshold:

$$
(1-m) v \pi<c_{S R}<\left[(1-m) v+\left(\frac{q}{3}\right)\right] \pi \quad \text { and } \quad m v \pi<c_{M C}<\left[m v+\left(\frac{q}{3}\right)\right]
$$

and sampling is still profitable:

$$
\frac{q \pi}{3}>c_{D W}
$$

Society loses socially valuable sample-based works because of the need to license when creating the derivative work slips below profitability:

$$
\left(\frac{q}{3}\right) \pi<c_{D W}<q \pi
$$

Therefore, there are benefits and costs from moving between a regime of no copyright at all to a regime of complete copyright.

\section{Copyright over derivative works with a de minimis threshold.}

Now suppose that $\bar{y}$ is strictly greater than zero, but is still less than one. The particular costs and benefits of moving to this intermediate level of copyright protection determine the optimal level of $\bar{y}$.

\footnotetext{
${ }^{34}$ See the end of the preamble to Section 3 for the three positive social value conditions.
} 
Case (1): $y^{*} \leq \bar{y}$. Among sample-based works with $y^{*}$ below the de minimis threshold, we gain any works for which the following relations hold:

$$
\frac{q \pi}{3}<c_{D W}<q \pi ; \quad m v \pi>c_{M C} ; \quad \text { and } \quad(1-m) v \pi>c_{S R}
$$

We lose both the original, preexisting work and the sample-based works for which the following relations hold:

$$
c_{D W}<\frac{q \pi}{3}
$$

meaning that the sample-based work would have been profitable, had the original works come into being;

$$
m v \pi<c_{M C} \quad \text { or } \quad(1-m) v \pi<c_{S R}
$$

meaning that without licensing revenue, at least one of the copyright owners of the original song will not make a profit; and

$$
m v \pi+\frac{q \pi}{3}>c_{M C} \quad \text { and } \quad(1-m) v \pi+\frac{q \pi}{3}>c_{S R}
$$

meaning that with the licensing revenue, the copyright owners of the original song would have made a profit, and thus seen fit to produce the original work.

Case(2): $\bar{y}<y^{*} \leq\left(\frac{1}{1-\left(\frac{2}{3}\right)^{\lambda}}\right) \bar{y}$. In this adjusted-sample case, we first need to revise the positive social value conditions slightly, to reflect the derivative work's decline in value:

- Derivative work: $[1-L(\bar{y})] q(1-l)-c_{D W}>0$

- Original recording: $\{(1-m) v+q(1-L(\bar{y})]\}(1-l)-c_{S R}-$ $c_{D W}>0$

- Original composition: $\{m v+q[1-L(\bar{y})]\}(1-l)-c_{M C}-$ $c_{D W}>0$

Assuming that those conditions hold, we can now discuss the socially valuable works that would be gained or lost as compared to the complete-copyright scenario. Among sample-based works with $y^{*}$ lying between the de minimis threshold and the largest 
sample length $y$ that is worth incurring the loss $L(y)$ to adjust, we gain sample-based works for which:

$$
\frac{q \pi}{3}<c_{D W}<[1-L(\bar{y})] \cdot q \pi
$$

which specifies that the derivative work, which was not profitable if the full sample was licensed, would be profitable with an adjusted sample. For this gain in the number of sample-based works created to occur, it also must be true that both

$$
m v \pi>c_{M C} \quad \text { and } \quad(1-m) v \pi>c_{S R}
$$

which guarantees that the original, sampled song will still be created, even without the licensing revenue.

As in Case (1), we lose both the original, preexisting work and the sample-based works for which the following relations hold:

$$
c_{D W}<\frac{q \pi}{3}
$$

meaning that the sample-based work would have been profitable, had the original works come into being;

$$
m v \pi T<c_{M C} \quad \text { or } \quad(1-m) v \pi<c_{S R}
$$

meaning that without licensing revenue, at least one of the copyright owners of the original song will not make a profit; and

$$
m v \pi+\left(\frac{q \pi}{3}\right)>c_{M C} \quad \text { and } \quad(1-m) v \pi+\frac{q \pi}{3}>c_{S R}
$$

meaning that with the licensing revenue, the copyright owners of the original song would have made a profit, and thus seen fit to produce the original work. These conditions for losing the original work are the same as in case (1) because, regardless of the sampler's particular $y^{*}$, the requirement for a work to be lost is that it was being made before and that it will no longer be licensed thanks to the de minimis exception and the ability to adjust sample length downward. 
In addition, society could lose some value from samples being adjusted in derivative works that were already being made under the complete-copyright scenario. For this to occur, $c_{D W}$ would have to be less than $\frac{q \pi}{3}$, so that the work was getting made in the complete-copyright scenario. But if it's also the case that $[1-L(\bar{y})] \cdot q \pi>\frac{q \pi}{3}<c_{D W}$, then the sampler will adjust the sample to make more profit. In that event, society gets only the fraction $[1-L(\bar{y}]$ times the original social value of the samplebased work. That loss in social value must also count in the ledger when assessing the gain and loss from introducing a de minimis threshold $\bar{y}$ greater than zero.

Case (3): $y^{*}>\left(\frac{1}{1-\left(\frac{2}{3}\right)^{\lambda}}\right) \bar{y}$. In this event, no works are gained or lost, nor is any social value lost, with respect to the completecopyright scenario. No sampler with a $y^{*}$ this high will find it profitable to adjust their sample; he or she will either license the sample or choose not to produce the sample-based work at all.

\subsection{The optimal threshold for copyright pro- tection}

As in the previous section, the optimal policy will depend on the distributions of the random variables and the values of the parameters. Some general conclusions might be drawn about which regime the costbenefit calculation would be likely to recommend. In contrast to Green and Scotchmer's concerns in the patent context about whether basic research will occur, the copyright context suggests that policy makers should have concerns about balancing the incentives of both upstream and downstream creators (rather than having a primary concern on just the upstream creators).

In the music context, ex ante licensing does occur, as when copyright holders hire other musicians to remix their songs. But many samplers do not know in advance which samples, sounds, and combinations of sounds will occur to them and sound good together. With 
ex post licensing, the creator of the derivative work typically has no opportunity to share their costs with the copyright owners of the original work. This is especially true in light of the distance in time that can often occur between samplee and sampler, described in Section 3.2. This makes possible a number of situations in which samplers' incentive problem results in derivative works not being created. In those instances, copyright's regime for sampling can backfire. When the derivative work is not created, the copyright holder in the preexisting work receives no licensing revenue. This endangers the preexisting work's creator's ability to solve his or her incentive problem.

A positive de minimis threshold gives copyright law a mechanism to put some derivative works outside the reach of copyright, alleviating the incentive problem for some creators of derivative works and potentially providing some balance. While not perfect, sample length is an attractive policy lever because it is objective, not requiring private parties or judges to engage in aesthetic assessments to understand the reach of copyright law. But the de minimis threshold may entice some samplers to alter the samples they use from their desired lengths. That consequence has both advantages and drawbacks, in terms of the number of works created and the value of the works created. With a relatively small de minimis threshold, however, both these effects will be relatively small. Based on the simple model presented so far, it seems possible that some positive de minimis threshold would have broad social benefits.

\section{Conclusion}

This chapter has addressed the problems facing creators of derivative works in the music industry, particularly those musicians engaged in sampling or collage. Specifying a model of the division of profit between the copyright holders of preexisting works and the creator of a prospective derivative work, I have attempted to isolate what I see as the fundamental inefficiency involved. Because of factors the separa- 
tion in time between the original work and the derivative work, I have argued that society has reason to be concerned about both samplees' and samplers' incentives at the same time, for the sake of both groups.

Although the model of Sections 3 focuses on the difficulties that can arise in sample licensing because of non-contractibility, in truth the situation is both better and worse than that for musicians who sample. On the plus side, musicians can adjust the samples they use, how may samples they use, or even alter their method of musical borrowing from sampling to "replaying" small pieces of compositions themselves (which reduces the licensing burden to one type of license). Musicians can also adjust the method by which they release their music to the public; in essence, they have choice over their particular business model. The tradeoffs involved can result in differently situated musicians making different business-model choices. ${ }^{35}$ Consideration of copyright law's policy toward sampling should take into account the flexibility that samplers have on the margins of both artistic choices and business models.

Extending the model to the multiple-sample situation shows that the real-world situation of musicians who sample can be worse than the stylized model suggests. Moreover, market imperfections like transaction costs, uncertainty, and asymmetric information would exacerbate the division-of-profit problem. For example, adding transaction costs to the copyright-in-samples regime would create a deadweight loss that would lead the copyright regime to fare worse (under any assumptions) than the no-copyright-in-samples regime. The appropriate policy solution to the inefficiencies involved in sample licensing requires a detailed investigation of the institutional features of the music industry, a much longer project that I have participated in separately. ${ }^{36}$ This chapter seeks to lay a foundation for that work by

\footnotetext{
${ }^{35} \mathrm{~A}$ numerical simulation with calibrated assumptions about various music-industry parameters can illustrate how different business models become more and less attractive under which conditions. See Peter DiCola, "An Economic Model of Sampling, Cover Versions, and Musical Collage," (working paper on file with author, 2006).

${ }^{36}$ See Kembrew Mcleod \& Peter DiCola, Creative License: The LaW and
} 
demonstrating that one cannot determine the optimal policy with a simplistic appeal to property rights, as the Sixth Circuit Court of Appeals took in Bridgeport. The division-of-profit problem, applied to the context of sample licensing, shows that the interaction between upstream and downstream authors is complex enough to resist such a priori generalizations.

\section{A Appendix: A three-person licens- ing game}

Three people bargain to divide a pie of size $q$. Player 1 is the licensee, while Players 2 and 3 are the licensors. Their positions are asymmetric. Player 1 deals with each other player in bilateral negotiations. Players 2 and 3 act simultaneously during each round and cannot communicate to strategize or collude. But all parties have complete information about the structure of the game and the potential payoffs.

Negotiations continue indefinitely. The discount factor is the same for all players and is $\delta \in(0,1]$. Deals are binding once made but no bankruptcy allowed. So if the pie is not produced, no money is owed. The breakdown payoff for each player is zero.

When a deal is accepted early, the player gets paid in terms of that periods dollars, with no further discounting, even if the game carries on and the pie is not produced until a later period. ${ }^{37}$ If one bilateral deal is made between two players (say, Player 1 and Player 2) but the other bilateral deal (between Player 1 and Player 3) is not, then the remaining two players engage in the alternating-offers game of Rubinstein, ${ }^{38}$ which splits the pie $\left(\frac{1}{1+\delta}, \frac{\delta}{1+\delta}\right)$ between the first offeror and the first offeree.

Game play proceeds as follows:

Culture of Digital Sampling (Duke Univ. Press, forthcoming 2010).

${ }^{37}$ See Suchan Chae \& Jeong-Ae Yang, An N-Person Pure Bargaining Game, 62 J. ECon. THEORY 86, 89 (1994).

${ }^{38}$ See Rubinstein, supra. 
1. In round one, Player 1 simultaneously solicits offers from Players 2 and 3, resulting in the following payoffs for (Player 1, Player 2, Player 3): $\left(q-a_{1}-b_{1}, a_{1}, b_{1}\right)$. Players 2 and 3 each make their offers. There are four possible scenarios, based on the offers made in the first round of bargaining.

(a) If Player 1 accepts both offers, then the game ends, with payoffs equal to: $\left(q-a_{1}-b_{1}, a_{1}, b_{1}\right)$.

(b) If Player 1 accepts $2 \mathrm{~s}$ price but rejects $3 \mathrm{~s}$, then we have a bilateral game between 1 and 3 , in which 1 makes the first offer. The remaining pie size is: $\delta q-a_{1}$ and the resulting payoffs are: $\left(\frac{\delta q-a_{1}}{1+\delta}, a_{1}, \frac{\delta^{2} q-\delta a_{1}}{1+\delta}\right)$.

(c) If Player 1 rejects $2 \mathrm{~s}$ price but accepts $3 \mathrm{~s}$, then we have a bilateral game between 1 and 2, in which 1 makes the first offer. The remaining pie size is: $\delta q-b_{1}$ and the resulting payoffs are: $\left(\frac{\delta q-b_{1}}{1+\delta}, \frac{\delta^{2} q-\delta b_{1}}{1+\delta}, b_{1}\right)$

(d) If 1 rejects both 2 and 3 price quotes, then we reach round two.

2. In round two, a similar 3-person game to round one is played for a pie size $\delta q$ and with the difference that player 1 make the first offers. In the event that the game reaches round two, there are four scenarios:

(a) Both Players 2 and 3 can accept, ending the game with payoffs: $\left(\delta\left(q-a_{2}-b_{2}\right), \delta a_{2}, \delta b_{2}\right)$.

(b) Player 2 could accept while player 3 rejects. This launches a bilateral game between Player 1 and Player 3, with Player 3 making the first offer and a pie size of $\delta^{2} q-\delta a_{2}$. The resulting payoffs are: $\left(\frac{\delta^{3} q-\delta^{2} a_{2}}{1+\delta}, \delta a_{2}, \frac{\delta^{2} q-\delta a_{2}}{1+\delta}\right)$.

(c) Player 2 could reject while player 3 accepts. This launches a bilateral game between Player 1 and Player 2, with Player 2 offering first and a pie size of $\delta^{2} q-\delta b_{2}$. The resulting payoffs are: $\left(\frac{\delta^{3} q-\delta^{2} b_{2}}{1+\delta}, \frac{\delta^{2} q-\delta b_{2}}{1+\delta}, \delta b_{2}\right)$.

(d) Both Players 2 and 3 could reject. Now we play the orig- 
inal three-person game, with Players 2 and 3 offering first, for a pie of size $\delta^{2} q$. The structure is thus recursive. Call the payoffs in the subgame $\left(\delta^{2}(q-a-b), \delta^{2} a, \delta^{2} b\right)$, with no subscripts on the offers.

To solve this infinitely repeated game, I follow the solution method outlined in Gibbons. ${ }^{39}$ Taking the second round of bargaining first, what would it take for both Player 2 and Player 3 to accept Player 1s offers? In other words, what are the incentive constraints for a subgame-perfect equilibrium?

The first four conditions determine the optimal offers by Player 1 in round two of bargaining, $a_{2}^{*}$ and $b_{2}^{*}$, as a function of the continuation payoffs $a$ and $b$ in the event of the entire supergame being repeated (i.e., when both Player 2 and Player 3 reject Player 1's offers in the second round). These conditions can be understood as Player 1 avoiding creating a prisoners' dilemma among Player 2 and Player 3. The final three conditions consider what would it take, in the first round of bargaining, for Player 1 to accept both Player 2's and Player 3 s offers.

1. Player 2's payoff $\delta a_{2}$ must be greater than or equal to $\delta^{2} a$, the continuation payoff if neither Player 2 nor Player 3 accepts.

2. Player 3's payoff $\delta b_{2}$ must be greater than or equal to $\delta^{2} b$, the continuation payoff if neither Player 2 nor Player 3 accepts.

3. Player 2's payoff $\delta a_{2}$ must also be greater than or equal to $\frac{\delta^{2} q-\delta b_{2}}{1+\delta}$, which is Player 2's payoff if Player 3 accepts while Player 2 rejects.

4. Player 3's payoff $\delta b_{2}$ must also be greater than or equal to $\frac{\delta^{2} q-\delta a_{2}}{1+\delta}$, which is Player 3's payoff if Player 2 accepts while Player 3 rejects.

\footnotetext{
${ }^{39}$ Robert Gibbons, Game Theory for Applied Economists 68-71 (1992) (citing Rubinstein, supra, and Avner Shaked \& John Sutton, Involuntary Unemployment as a Perfect Equilibrium in a Bargaining Model, 52 Econometrica 1351 (1984)).
} 
5. It must be the case that $q-a_{1}-b_{1} \geq \delta\left(q-a_{2}^{*}-b_{2}^{*}\right)$, so that it is worthwhile from Player 1's perspective not to reject both offers.

6. It must also be the case that $q-a_{1}-b_{1} \geq \frac{\delta q-a_{1}}{1+\delta}$, so that Player 1 does not have incentive to accept Player 2's offer but reject Player 3's offer.

7. Finally, and similarly, it must be true that $q-a_{1}-b_{1} \geq \frac{\delta q-b_{1}}{1+\delta}$, so that Player 1 does not have incentive to accept Player 3's offer but reject Player 2's offer.

This determines the optimal offers by Player 2 and Player 3 in round one, as a function of the second-round continuation payoffs $a$ and $b$. In other words, to calculate the equilbrium, we will aim to set $a_{1}^{*}(a)=a$ and $b_{1}^{*}(b)=b$. Conditions (3) and (4) imply (1) and (2), but not the reverse. So one must solve (3) and (4), the binding incentive constraints, for Player 1s optimal second-round offers. Then, based on that, we can get Player 1s best second-round payoff. Next, one can solve equation (5) based on that result. It turns out that condition (5) implies conditions (6) and (7), and the game is solved. The equilibrium payoffs (after some algebraic work based on the solution strategy just described), are:

$$
\left(\delta-\frac{2 \delta^{2}}{\delta+2}, \frac{\delta^{2}-\delta+2}{2 \delta+4}, \frac{\delta^{2}-\delta+2}{2 \delta+4}\right)
$$

which approaches $\left(\frac{1}{3}, \frac{1}{3}, \frac{1}{3}\right)$ as $\delta$ approaches 1 . 